\title{
Serial Ultrasonographic Measurements to Estimate Age and Viability in Bos indicus Embryos
}

\author{
Ana Lucia Malvaez ${ }^{1}$, Carlos Salvador Galina1*, Ivette Gutierrez², Manuel Corro², \\ Jose Luis Pablos ${ }^{3}$
}

${ }^{1}$ Departamento de Reproducción, Facultad de Medicina Veterinaria y Zootecnia, Universidad Nacional Autónoma de México, Ciudad Universitaria, Ciudad de México, México

${ }^{2}$ Centro de Enseñanza, Investigación y Extensión en Ganadería Tropical, Facultad de Medicina Veterinaria y Zootecnia, Universidad Nacional Autónoma de México, Tlapacoyan, Veracruz, México

${ }^{3}$ Departamento de Genética y Bioestadística, Facultad de Medicina Veterinaria y Zootecnia, Universidad Nacional Autónoma de México, Ciudad Universitaria, Ciudad de México, México

Email: *cgalina@unam.mx

How to cite this paper: Malvaez, A.L., Galina, C.S., Gutierrez, I., Corro, M. and Pablos, J.L. (2019) Serial Ultrasonographic Measurements to Estimate Age and Viability in Bos indicus Embryos. Open Journal of Veterinary Medicine, 9, 91-99. https://doi.org/10.4236/ojvm.2019.97008

Received: May 6, 2019

Accepted: July 22, 2019

Published: July 25, 2019

Copyright $\odot 2019$ by author(s) and Scientific Research Publishing Inc. This work is licensed under the Creative Commons Attribution International License (CC BY 4.0).

http://creativecommons.org/licenses/by/4.0/

\begin{abstract}
Early pregnancy diagnosis is a very important routine management to identify non-pregnant cows in order to keep an optimum reproductive efficiency both for dairy and beef cows. Ultrasound equipment allows estimating the viability and size of the embryo during early gestation. With the aim of assessing age and viability of Bos indicus embryos between 24 and 35 days of gestation, 55 cows were divided into 4 clusters. These clusters were conformed according to the first day that an echogenic structure was seen inside the embryonic vesicle (Group 1: day 24, Group 2: day 26, Group 3: day 27 and Group 4: day 28). The age of the embryos was estimated from the date of AI. Three progressive serial measurements of their length were made within 2 to 5 days. With a model GEE (Generalized Estimating Equations), the effect of days was evaluated to compare the second measurement with the first one and the former with the third observation. No differences in the size of the embryos were observed between the first evaluation (24 days) and the second (28 days) $(\mathrm{P}=0.387)$. Also, simple linear regression analysis found a positive linear association between the size of the embryo and gestation days $\left(\mathrm{R}^{2}=\right.$ $0.593)$ with an average growth of $0.078 \mathrm{~cm}$ per day $(\mathrm{P}=0.001)$. In conclusion, the variation between measurements at a given time does not allow estimating with precision the exact day of gestation. Nonetheless, serial measurements are useful to estimate the healthy growth of the embryo from day 26 of gestation.
\end{abstract}




\section{Keywords}

Zebu Cattle, Embryo Measurement, Reproduction, Tropics

\section{Introduction}

Embryo and fetal losses have been related to many factors, which have been described as genetic, physiological, endocrine and environmental [1]. It has been reported that there is a $15 \%$ of embryonic death between days 28 to 42 of gestation and could be as severe as 30\% [2] [3]. In comparison, fetal death between 42 to 62 days is only $6.3 \%$ and it decreases from day 56 to 98 to $3.4 \%$ [4]. Factors such as climate, general health of cattle and biosecurity [5] can cause mortality with various grades of severity.

A great advantage of using ultrasonography (US) is that it gives the opportunity to sequentially measure the same embryo on different phases of development and to be able to identify variations about its size. These variations could have negative consequences on gestation such as embryonic death thus affecting cattle performance [6] [7].

Growth curves are defined as the increase of geometrical characteristics related to the time of a structure [6]. Changes on the size of the embryo allow us to establish a relationship with gestational age [4] [8]. Nowadays, there is US equipment allowing to estimate the size of the embryo or a fetus using established measurements such as distance between the crown to the rump. Measuring these structures is known to be the most reliable method to estimate the age of the embryo [4] [7].

According to Fricke [9], when pregnancy diagnosis with ultrasound is conducted between day 26 and 33 post IA, sensitivity and specificity can be $97.7 \%$ and $87.7 \%$ respectively. However, there are some factors that affect pregnancy diagnosis. Such as age of female (heifer or adult cows); periodicity of the examine, equipment, frequency of the transducer and experience of the operator [10].

Precision on pregnancy diagnosis by using ultrasonography may be highly variable. It depends on many factors such as equipment, frequency of the transducer, periodicity of the examination, age and number of calvings of the female, the stage on which the exam is being held and of course criteria and experience of the operator [10].

According to Laven [11], there are computer programs which relate gestation days to different measurements of the embryo and fetal age creating a unique line with a better adjustment by using conversions that ignore the inherent variability of any natural system. Nevertheless, there is a "normal" range of sizes for each gestation day and it has to be considered that a correlation of $100 \%$ is unlikely because these programs give only one figure, thus no variation can be shown. Also, it may be bigger for some days and not for others. Moreover, it has 
to be taken in consideration that these measurements were developed for Bos Taurus cattle and applying them to Bos indicus may be arbitrary, considering variations in the latter species previously reported [8] [12].

Therefore, the main objective of this work was to characterize by serial examinations the growth and viability of the embryo between days 24 to 36 on Bos indicus cows.

\section{Material and Methods}

The Animal Care Internal Committee of the Faculty of Veterinary Medicine and Animal Science of the National Autonomous University of Mexico (FMVZ-UNAM) approved the methods used during the present research in accordance with The Code of Ethics of the World Medical Association (Declaration of Helsinki).

\subsection{Location}

The study was undertaken at the Centre for Teaching, Research and Extension in Tropical Animal Husbandry belonging to the Faculty of Veterinary Medicine of the National Autonomous University of Mexico, which is located in the state of Veracruz, Mexico, at $20^{\circ} 4^{\prime} \mathrm{N}$ and $97^{\circ} 3^{\prime} \mathrm{W}$. The climate is hot and humid, without a defined dry season. The average yearly rainfall is $1840 \mathrm{~mm}^{3}$ and the average temperature ranges between $14^{\circ} \mathrm{C}$ and $35^{\circ} \mathrm{C}$ [13].

\subsection{Animals}

Eighty multiparous Bos indicus females between three and seven years old were selected. All chosen cows had calved in a 45 days period and ranging from 3.0 to 3.5 body condition score according to the procedure described by Edmonson et al. [14]. All animals remained in the same pasture, in a rotational paddocks system based on Cynodonnlemfuensis, Paspalum spp. And Axonopus spp. with mineral salts provided.

\subsection{Reproductive Management}

In all cows, estrus was synchronized using a progesterone-releasing device $\left(\mathrm{CIDR}^{\mathrm{TM}}, 1.9 \mathrm{~g}\right.$ natural progesterone Zoetis ${ }^{\oplus}$, Mexico). The device was withdrawn at 9 days after insertion. At this time, $25 \mathrm{mg}$ of prostaglandin F2 $\alpha$ (Dinoprost, Lutalyse, Zoetis ${ }^{\infty}$, Mexico) was injected intramuscularly. Estrus detection was carried out at 10,11, 12 and 13 days for three hours at 09:00 and 15:00, the riding behavior was used as the main indicator of estrus [15]. A patch in the rump (Scratch Pads, Magenta Direct, and Ireland) was placed for assistance in identification of the nocturnal activities. Artificial insemination (AI) was carried out with an AM-PM system.

\subsection{Pregnancy Diagnosis and Measurement of the Embryo}

Transrectal ultrasonography was performed to diagnose pregnancy and measure the embryo, by using an ultrasound device (Aloka SSD-500, Aloka, Tokio, Ja- 
pan) with a linear transductor of $7.5 \mathrm{MHz}$. Cows were considered as probably pregnant if they did not show signs indicative of an eminent return to estrusat 24 days after AI. Animals diagnosed as not pregnant, through 2 serial exams, were removed from the study $(n=25)$. On animals diagnosed pregnant $(n=55)$ the length $(\mathrm{cm})$ and viability of the embryo was registered according to the procedure described by Rosiles et al. [12].

These cows were distributed in four groups according to the first day of an echogenic structure was observed inside the embryonic vesicle. Each embryo was assigned to a group according to first evaluation at day 24, 26, 27 or 28 . The first evaluation was recorded on the dates indicated above, a second and third evaluation were undertaken between 2 to 4 days in respect to the first or second measurement. The age of the embryos was estimated from the date of AI. A screenshot was taken to measure the embryo by using the ultrasound-measuring program. Measures were taken between day 24 and day 36 after AI.

\subsection{Statistical Analysis}

With a model GEE (Generalized Estimating Equations model) the effect of days was evaluated to compare the second measurement with the first one and the former with the third observation. The estimators of the effects of the model correspond to a supposed structure of independence of the errors [16] [17]. A linear regression analysis was performed in order to know the relationship between the length and age of the embryo.

\section{Results}

Of the total number of cows selected for the study $(n=80) 55$ became pregnant. Group 1, consisted of $15 \%$ of the animals (8/55), the first observation was undertaken on day 24 of gestation, a second observation on day 28 and a third one on day 30 . Group 2 with $16 \%$ (9/55) of the embryos were observed on day 26 , on day 29 and finally on day 33. Group 3 with 36\% (20/55), the measurements were carried out on day 27 , on day 30 and on day 35 of gestation. Finally, group 4 with $33 \%$ (18/55) of the embryos were measured on day 28 , day 31 and day 36 .

Figure 1 shows the growth trend between the three means of each group with a confidence interval of $95 \%$. In group 1 (Figure 1(a)) the embryos recorded for days 24,28 and 30 had a mean of $0.39 \pm 0.16 \mathrm{~cm}, 0.45 \pm 0.17 \mathrm{~cm}$ and $1.27 \pm 0.51$ $\mathrm{cm}$ respectively. The means and confidence intervals of the first two measurements had a similar distribution, in contrast to the third measurement in which the values parted. In group 2 (Figure 1(b)) embryos presented a mean of $0.65 \pm$ $0.12 \mathrm{~cm}$ for day $26,0.81 \pm 0.11 \mathrm{~cm}$ on day 29 and $0.10 \pm 0.29 \mathrm{~cm}$ on day 33 . The confidence intervals of the first and the second group overlap in the same way as those of the second with the third group. Groups 3 and 4 (Figure 1(c) and Figure 1(d)) showing ascending and apparently linear growing trend. The embryos for group 3 recorded at days 27,30 and 35 a mean of $0.87 \pm 0.09 \mathrm{~cm}, 1.12 \pm 0.12$ $\mathrm{cm}$ and $1.41 \pm 0.11 \mathrm{~cm}$ respectively and for group 4 on days 28,29 and 31 an 


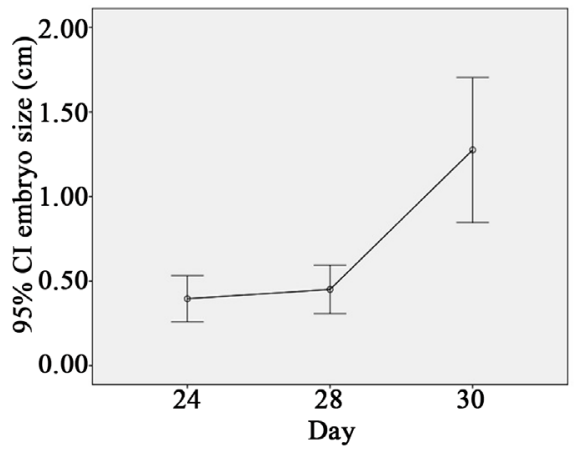

(a)

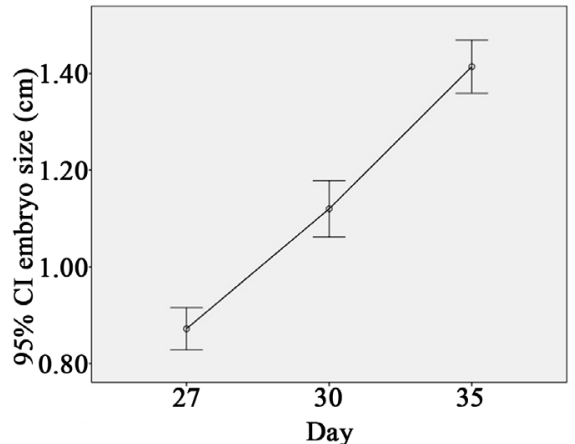

(c)

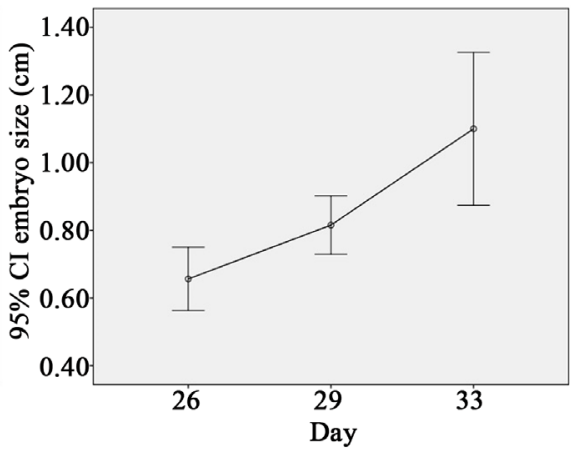

(b)

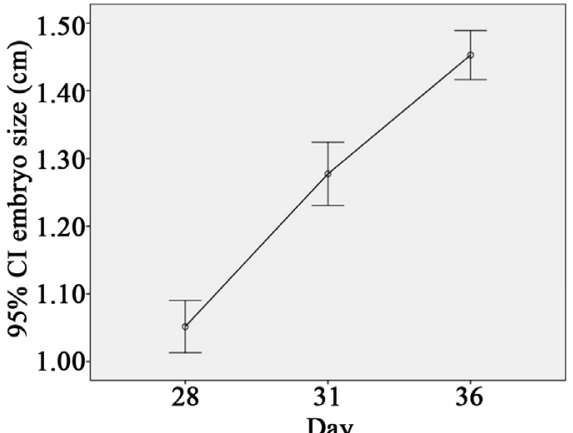

(d)

Figure 1. Embryonic growth trend confidence interval of $95 \%$ for the means of group 1 (evaluation days 24, 28 and 30; Figure 1(a)), group 2 (evaluation days 26, 29 and 33; Figure 1(b)); group 3 (evaluation days 27, 30 and 35; Figure $1(\mathrm{c})$ ) and group 4 (evaluation days 28, 31 and 36; Figure 1(d)). (a) Group 1. Mean and confidence interval of the first $(\bar{X}=0.39 \pm 0.16 \mathrm{~cm})$, second $(\bar{X}=0.45 \pm 0.17 \mathrm{~cm})$ and third measure $(\bar{X}=1.27 \pm$ $0.51 \mathrm{~cm})$; (b) Group 2. Mean and confidence interval of the first $(\bar{X}=0.65 \pm 0.12 \mathrm{~cm})$, second $(\bar{X}=0.81 \pm 0.11 \mathrm{~cm})$ and third measure $(\bar{X}=1.10 \pm 0.29 \mathrm{~cm}) ;(\mathrm{c})$ Group 3 . Mean and confidence interval of the first $(\bar{X}=0.87 \pm 0.09 \mathrm{~cm})$, second $(\bar{X}=1.12 \pm$ $0.12 \mathrm{~cm}$ ) and third measure $(\bar{X}=1.41 \pm 0.11 \mathrm{~cm})$; (d) Group 4. Mean and confidence interval of the first $(\bar{X}=1.05 \pm 0.07 \mathrm{~cm})$, second $(\bar{X}=1.27 \pm 0.09 \mathrm{~cm})$ and third measure $(\bar{X}=1.45 \pm 0.07 \mathrm{~cm})$.

average of $1.05 \pm 0.07 \mathrm{~cm}, 1.27 \pm 0.09 \mathrm{~cm}$ and $1.45 \pm 0.07 \mathrm{~cm}$.

Table 1 shows the average increase in the length of the embryo between the first and second measure and between the second and third measure in each one of the days as well as the p-value of the mean differences.

Integrating the data according to the observation date, a joint analysis was made considering all the observations and a simple linear regression analysis was performed. The scatter plot of the size of the embryos between days 24 to 36 is shown in Figure 2.

Data shows that there is a positive linear association between the size of the embryo and the days of gestation $\left(\mathrm{R}^{2}=0.593\right)$ with an average increase in the length of the embryo of $0.078 \mathrm{~cm}$ per day $(\mathrm{P}=0.001)$.

\section{Discussion}

The final pregnancy rate was $68 \%$ contrasting to previous reports which did not 


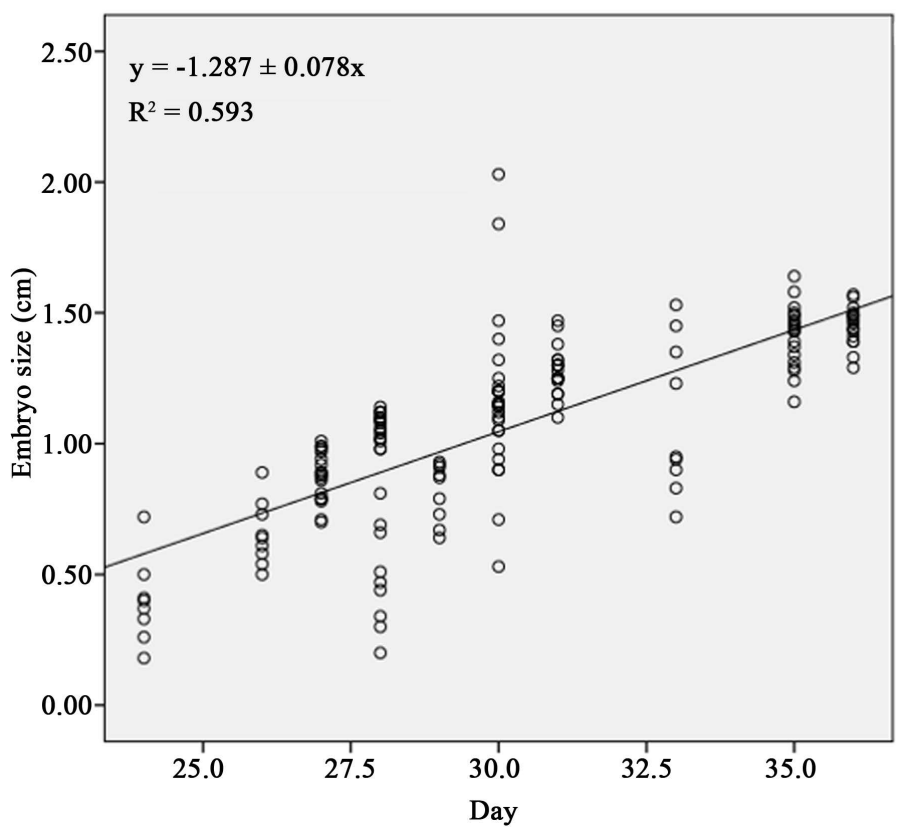

Figure 2. Linear regression of the length $(\mathrm{cm})$ of the embryo from 24 to 36 days.

Table 1. Mean differences in the length of the embryos in the days of measurement.

\begin{tabular}{|c|c|c|c|c|}
\hline \multirow{2}{*}{ Group } & \multicolumn{2}{|c|}{ Daysofmeasurement } & \multirow{2}{*}{$\begin{array}{l}\text { Average increase in the } \\
\text { length of the embryo }(\mathrm{cm})\end{array}$} & \multirow{2}{*}{ P-value } \\
\hline & Fromday & Today & & \\
\hline \multirow{2}{*}{1} & 24 & 28 & 0.05 & 0.387 \\
\hline & 28 & 30 & 0.82 & 0.001 \\
\hline \multirow[b]{2}{*}{2} & 26 & 29 & 0.15 & 0.001 \\
\hline & 29 & 33 & 0.28 & 0.012 \\
\hline \multirow{2}{*}{3} & 27 & 30 & 0.24 & 0.001 \\
\hline & 30 & 35 & 0.29 & 0.001 \\
\hline \multirow{2}{*}{4} & 28 & 31 & 0.22 & 0.001 \\
\hline & 31 & 36 & 0.17 & 0.001 \\
\hline
\end{tabular}

obtain percentages higher than $25 \%$ in programs of artificial insemination (AI) in the Mexican tropics [18] [19]. Nevertheless, there are reports of fertility up to $60 \%$ with synchronization protocols, this percentage may vary depending on the body condition, postpartum period, season of the year, among others [5].

From day 24 after AI, first embryos of group 1 were visible coinciding with studies by Curran, Pierson and Ginther [20], DesCôteaux, Colloton and Gnemmi [4], Totey et al. [8] and Rosiles et al. [12] where it is mentioned that embryos can be seen in a range between 19 and 24 days as an echogenic protuberance inside the embryonic vesicle. In the case of group 2, observations commenced at day 26 according to Chaffaux, Valon and Martínez [21] and Pierson and Ginther [22] that reported lack of precision prior to this date.

Differences between days were found when measuring the embryo starting at 
day 26 and further measurements confirmed the linear growth of the embryo (Figure 1(b)). This was not the case in embryos whose first measurement started at day 24 (Figure 1(a)). Our results point out that it is reasonable to recommend starting on day 26. According to Fricke [9], when an early diagnosis is done between 26 and 33 days post AI by ultrasonography, sensitivity and specificity of pregnancy be until $97.7 \%$ and $87.7 \%$ respectively. Early identification of nonpregnant cows post-breeding improves reproductive efficiency and pregnancy rate in cattle by decreasing the interval between AI services and increasing AI service rate [9] [23]. Nonetheless, it should be bear in mind that loss of embryos could account for as much as $30 \%$ of embryo death [3], thus an early diagnosis could be a useful tool.

Linear regression, with all embryos that were evaluated, evidenced the range of the data, being larger on days 28,30 and 33 with an increment of $0.078 \mathrm{~cm}$ per day on the length of the embryo. Similar results were reported by Rosiles et al. [12] where measurements show greater amplitude between days 28 and 32, with a similar increment in size per day of $0.085 \mathrm{~cm}$. Ginther [24] and Pierson and Ginther [22] mention a mean growth of $0.11 \mathrm{~cm}$ from day 26 to 50 . A variation in the results, particularly in the early stages of embryo visualization, is very likely the consequence of inaccuracies of the operator or difficulties in the placement of the US probe, particularly in mature cows [25].

A statistical comparison between the means obtained on the days of evaluation with previous reports was performed to ascertain the value of the present report. For example, Ginther [24]; Pierson and Ginther [22] and Rosiles et al. [12]. It was observed that on the first two reports the means are statistically different from the days evaluated in the present study with an exception on days 28 and 30. This may be due to variation in the accuracy of the measurement particularly on these days as can be observed on graph 2 . Regarding the reported measures by Rosiles et al. [12], it was found that there is a significant difference only on days $27,28,30$ and 36 , this may be attributable to the fact that the study of Rosiles et al. [12] was performed in Bos indicus cattle whilst Ginther [24] and Pierson and Ginther [22] published their results on Bos Taurus cattle.

In the present study, we found it is possible to estimate the age the embryo with reasonable precision in Bos indicus cows. And this event accompanied by an accurate observation of the heartbeat would suggest the healthy status of the embryo. Measuring the length of the embryo by ultrasound does not allow to precisely determining its age due to the wide distribution of observations between 28 and 33 days. However, ultrasound can be a reliable tool to monitor the development of the embryo starting on day 26 ; it also allows identifying changes on its growing pattern that may indicate a loss of gestation and thus having the opportunity of reintroducing these animals to a reproductive program.

\section{Conflicts of Interest}

The authors declare no conflicts of interest regarding the publication of this paper. 


\section{References}

[1] Diskin, M.G. and Morris, D.G. (2008) Embryonic and Early Foetal Losses in Cattle and Other Ruminants. Reproduction in Domestic Animals, 43, 260-267. https://doi.org/10.1111/j.1439-0531.2008.01171.x

[2] Galicia, L., Estrada, K., Galina, C., Pérez, G., Romero, J. and Molina, S. (2006) Ultrasonography as Aid for Early Pregnancy Diagnosis in Zebu Cattle in a Natural Mating Programme. Journal of Applied Animal Research, 29, 53-58. https://doi.org/10.1080/09712119.2006.9706570

[3] Holroyd, R., Entwistle, K. and Shepherd, R. (1993) Effects on Reproduction of Estrous Cycle Variations, Rectal Temperatures and Liveweights in Mated Brahman Cross Heifers. Theriogenology, 40, 453-464. https://doi.org/10.1016/0093-691X(93)90399-P

[4] DesCôteaux, L., Colloton, J. and Gnemmi, G. (2009) Practical Atlas of Ruminant and Camelid Reproductive Ultrasonography. Wiley-Blackwell, Hoboken, NJ. https://doi.org/10.1002/9781119265818

[5] González, P., Dávalos, F. and Rodríguez, R. (2015) Estado del arte sobre investigación e innovación tecnológica en ganadería bovina tropical. Redgatro-Conacyt, México.

[6] Ali, A. and Fahmy, S. (2008) Ultrasonographic Fetometry and Determination of Fetal Sex in Buffaloes (Bubalus bubalis). Animal Reproduction Science, 106, 90-99. https://doi.org/10.1016/j.anireprosci.2007.04.010

[7] Fitzgerald, A.M., Ryan, D.P. and Berry, D.P. (2015) Factors Associated with the Differential in Actual Gestational Age and Gestational Age Predicted from Transrectal Ultrasonography in Pregnant Dairy Cows. Theriogenology, 84, 358-364. https://doi.org/10.1016/j.theriogenology.2015.03.023

[8] Totey, S.M., Singh, G., Taneja, M. and Talwar, G.P. (1991) Ultrasonography for Detection of Early Pregnancy Following Embryo Transfer in Unknown Breed of Bosindicus Cows. Theriogenology, 35, 487-497.

https://doi.org/10.1016/0093-691X(91)90445-J

[9] Fricke, P. (2002) Scanning the Future-Ultrasonography as a Reproductive Management Tool for Dairy Cattle. Journal of Dairy Science, 85, 1918-1926. https://doi.org/10.3168/jds.S0022-0302(02)74268-9

[10] Rajamahendran, R., Ambrose, D.J. and Burton, B. (1994) Clinical and Research Applications of Real-Time Ultrasonography in Bovine Reproduction: A Review. The Canadian Veterinary Journal, 35, 563-572.

[11] Laven, R. (2014) Estimating Fetal Age-How Accurate Are We? Livestock, 19, 217-220. https://doi.org/10.12968/live.2014.19.4.217

[12] Rosiles, V.A., Galina, C.S., Maquivar, M., Molina, R. and Estrada, S. (2005) Ultrasonographic Screening of Embryo Development in Cattle (Bos indicus) between Days 20 and 40 of Pregnancy. Animal Reproduction Science, 90, 31-37. https://doi.org/10.1016/j.anireprosci.2005.01.006

[13] Centro de Enseñanza, Investigación y Extension en Ganadería Tropical, C.E.I.E.G.T (2018) Tlapacoyan, Veracruz. Localización Geográfica. Facultad de Medicina Veterinaria y Zootecnia, México. http://www.fmvz.unam.mx/fmvz/centros/ceiegt/localizacion.html

[14] Edmonson, A., Lean, I., Weaver, L., Farver, T. and Webster, G. (1989) A Body Condition Scoring Chart for Holstein Dairy Cows. Journal of Dairy Science, 72, 68-78. https://doi.org/10.3168/jds.S0022-0302(89)79081-0

[15] Orihuela, A., Galina, C., Escobar, J. and Riquelme, E. (1983) Estrous Behavior Fol- 
lowing Prostaglandin F2 $\alpha$ Injection in Zebu Cattle under Continuous Observation. Theriogenology, 19, 795-809. https://doi.org/10.1016/0093-691X(93)90323-W

[16] Song, X.-K. (2007) Correlated Data Analysis: Modeling, Analytics, and Applications. Springer Science \& Business Media, New York.

[17] Penn State (2018) STAT 504-Analysis of Discrete Data. Lesson 12: Advanced Topics I-Generalized Estimating Equations (GEE). Pennsylvania State University, University Park, PA. https://onlinecourses.science.psu.edu/stat504/

[18] Alonso-Alanuza, L., Galina-Hidalgo, C.S., Maquivar-Linfoot, M., Romero-Zúñiga, J.J., Molina-Echeverry, I. and Carvajal-Arango, P. (2009) Evaluación de la fertilidad de hembras Bos indicus, de acuerdo a la intensidad del celo, manejadas en un programa de inseminación artificial a tiempo fijo en condiciones de trópico. Revista científica de veterinaria, 19, 639-644.

[19] Díaz, G., Galina, C., Basurto, C. and Ochoa, G. (2002) Effect of Natural Progesterone with and without Estradiol Benzoate on the Onset Signs of Oestrus, Ovulation and Pregnancy in Bos indicus Cattle Raised under Mexican Tropical Conditions. Archivos de Medicina Veterinaria, 34, 235-244.

https://doi.org/10.4067/S0301-732X2002000200009

[20] Curran, S., Pierson, R.A. and Ginther, O.J. (1986) Ultrasonographic Appearance of the Bovine Conceptus from Days 20 through 60. Journal of the American Veterinary Medical Association, 189, 1295-1302.

[21] Chaffaux, S., Valon, F. and Martinez, J. (1982) Evolution de l'image échographiqne du produit de conception chez la vache. Bulletin de PAcadémie Vétérinaire de France, 55, 213-221. https://doi.org/10.4267/2042/65200

[22] Pierson, R. and Ginther, O. (1984) Ultrasonography for Detection of Pregnancy and Study of Embryonic Development in Heifers. Theriogenology, 22, 225-233. https://doi.org/10.1016/0093-691X(84)90435-7

[23] Abdullah, M., Mohanty, T.K., Kumaresan, A., Mohany, A.K., Madkar, A.R., Baithalu, R.K. and Bhakat, M. (2014) Early Pregnancy Diagnosis in Dairy Cattle: Economic Importance and Accuracy of Ultrasonography. Advances in Animal and Veterinary Sciences, 2, 464-467. https://doi.org/10.14737/journal.aavs/2014/2.8.464.467

[24] Ginther, O.J. (1995) Ultrasonic Imaging and Animal Reproduction: Fundamentals. Equiservices Publishing, Cross Plains, WI.

[25] Peippo, J., Machaty, Z. and Peter, A. (2011) Terminologies for the Pre-Attachment Bovine Embryo. Theriogenology, 76, 1373-1379.

https://doi.org/10.1016/j.theriogenology.2011.06.018 